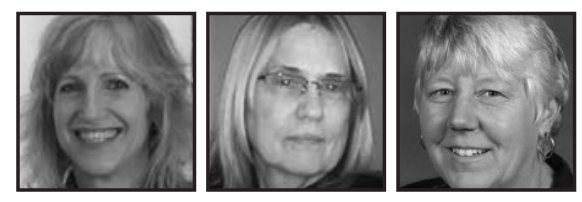

\title{
Storytelling to Teach Cultural Awareness: The Right Story at the Right Time
}

\author{
Mary McCullum Baldasaro, Nancy Maldonado, and Beate Baltes, \\ Walden University
}

\begin{abstract}
Stories contain the wisdom of the world, teaching cultural values, building community, celebrating cultural diversity, and preserving cultural identity. Where truth is suppressed, story is an instrument of epiphany and develops metaphorical understanding. A storytelling guild in Canada had been a cultural institution for 23 years, so when the center faced permanent closure, members were devastated. The purpose of this phenomenological study was to investigate the moment of this lived experience using interviews and focus groups. Findings indicated story strengthens content retention and language acquisition. These findings led to the development of a project focused on story-centered lessons for teachers.
\end{abstract}

\footnotetext{
he cried. When the talking feather was passed so that participants, students, and guests alike might share their thoughts and perceptions about the Blanket Exercise that they had just experienced, the Haudenosaunee Elder cried. Her tears, she insisted, were tears of gratitude that students, elementary students in their school classrooms, were finally hearing the stories that had so long been suppressed; gratitude that non-Aboriginal storytellers, teachers, and community leaders were stepping forward in unanticipated solidarity to ensure that the untold stories would find their rightful place in a new and deeper understanding of our common past on Turtle Island. It was the right story told at the right time.
} 
A storyteller believes in the power of story to heal the world. In this spirit, Kairos' Blanket Exercise seemed the ideal follow-up project to demonstrate the value and relevance of narrative that had been described by storyteller-participants who were interviewed for the prior research study. The essential premise is this: we remember things when they are part of a story. We remember better when the story is an oral story, a story told by heart, because our brains have to work hard to make sense of the words and to create the images. We remember best if the story touches our emotions, because emotional memory runs deep. Through story, the listener vicariously experiences the plight of the hero, and little distinction is made between real experience and vicarious experience. Anchor charts and bulleted lists have their places in education, but deeper essential learnings cry out for story.

In the research study, participants, all members of an Ontario storytellers' guild, had also been considering the value of place-not place value, a mathematical concept, but the importance of place, to story, to themselves as storytellers, because their own "place," their long-time storytelling center, had recently closed and they were adjusting to a new venue in a different city. Place theory comprises sense of place, place attachment, and place identity. Place has the capacity to situate memory (Smith, 2007; Waters, 2010), a construct deeply understood by the Inuit (Van Deusen, 2008) and other Aboriginal groups (Benson, 2003; Corntassel, Chaw-win-is, \& T'lakwadzi, 2009). Place attachment is strongly associated with sense of community (Long \& Perkins, 2007). Such attachment develops from interactive experiences, especially repeated experiences when the locus is lost or threatened and the community draws together (Chamlee-Wright \& Storr, 2009; Long \& Perkins, 2007). Because Kairos' Blanket Exercise is a narrative that concerns the loss of place in the most essential of all definitions, home and homeland, it reflects, profoundly, the critical intersection of narrative and place that was the focus of the initial research study.

\section{Introduction to the Project}

The project study, the creation of a comprehensive kit to facilitate the implementation of Kairos' Blanket Exercise, evolved from the research study discussed above. Stories are of primary significance in First Nation, Métis, and Inuit (FNMI) cultures. Stories have multiple dimensions, teaching as they do the history, the culture, the values, the roles of men and women, the importance of names and traditions. Such stories were largely misunderstood by the dominant western culture and trivialized as legend rather than Legend. Other stories, such as those of residential school experience, or starvation, 
were long disregarded and have only come to have credence more recently as they are corroborated by government documents (Weber, 2013a, 2013b; The Truth and Reconciliation Commission of Canada, 2012). These stories comprise a haunting untold history. One of the notions citizens cling to as a culture in Canada is of FNMI as the "other." One of the ways this has been accomplished is by sequestering FNMI peoples on reserves that are, for the most part, far from our understood civilization. These reserves are only the smallest fraction of the lands FNMI peoples once called home, lost through manipulation and un-honoured treaty, taken, not given, rarely recompensed. The events that led to the loss of FNMI land are the focus of the Blanket Exercise and the story activity kit, designed to create memory affectively through experience. The Blanket Exercise is the experiential telling of the largely unacknowledged and littleknown story of the loss of land to Canada's Indigenous people.

The lead researcher, an experienced storyteller, was introduced to Kairos' Blanket Exercise at a conference in July 2013 (Educating for the Common Good) just as she was completing the analysis for her research study. She recognized that the Blanket Exercise exemplified the powerful potential of narrative as described in the literature and by storyteller-participants, as well as its significant value as an introduction to First Nations, Métis, and Inuit content for the new (2013) Ontario Social Studies/History and Geography curriculum. From the feedback of other participants, she realized that minor adaptations would make the activity even more effective and memorable, and that the creation of an all-inclusive kit would make the story activity readily accessible to multiple schools, teachers, and students.

With the support of the itinerant teacher of the gifted, and the special education teacher at her school site, she trained a team of student leaders to facilitate the Blanket Exercise, under her supervision. She had the privilege of presenting the Blanket Exercise to the Waterloo Regional Aboriginal Academic Advisory Council (WRAAAC) for its feedback; this council is a local advisory committee comprising Aboriginal leaders, and superintendents from two boards of education.

The student team led the Blanket Exercise six times:

- For the students in each of the Grades 4 through 8 at the local school (including teachers and administration, as well as invited consultants and community members).

- For a workshop of identified gifted intermediate students from the local school board.

- For Education Week, before central cataloguing takes place, for parents, community members, and any students who missed the earlier presentation to their class. 
The lead researcher led the Blanket Exercise, with the assistance of the FNMI Consultant, for the FNMI representatives, one from each school, as board-wide professional development, with the intent that once in-serviced, teachers would be familiar and sufficiently comfortable to then use the kit to lead the Blanket Exercise at their own schools. This ripple effect will ensure that the largest possible number of students have the opportunity to experience the Blanket Exercise, sharing the common narrative and thus maximizing its impact. Following this presentation, the kit was catalogued at the resource centre and made available for use.

\section{Description of the Blanket Exercise}

This activity is a full-participation, feet-on, story activity that teaches the loss of First Nations lands through a series of historical events and treaties. The activity was developed by Kairos Canada (2013), an interfaith group that has given full permission and even encouragement to use and adapt the exercise. The lead researcher experienced the Blanket Exercise herself, and from the feedback of other participants realized that minor adaptations would make the activity even more effective and memorable. The creation of an all-inclusive kit makes the story activity readily accessible to multiple schools, teachers, and students.

For the presentation, the floor of the classroom or presentation room is spread with blankets (or towels) that touch each other. The whole center area is covered. Participants are usually invited to remove their shoes and stand on the covered area, which represents the northern part of Turtle Island (as North America is known in some Aboriginal traditions). Maps indicate the various groups who lived on and used and shared the land before the arrival of the Europeans. Participants are assigned the role of the Indigenous people, the original inhabitants. Two or three volunteers assist the narrator/leader by playing the role of Europeans. Coloured index cards, shells, or coloured sticks are distributed, determining the fate of individual participants. As the exercise progresses, a series of descriptive statements and proclamations outlining historical events and decisions that resulted in the loss of the land are read by the Europeans. As land is lost, the Europeans remove or fold towels, and participants may be "relocated" or required to join others on their "land." Certain proclamations result in towels being folded in half or into quarters, or even smaller. Others result in loss of life to participants, who move off the land to sit in a circle surrounding the ongoing narrative. Some participants are assigned to read statements (quotations) that express Aboriginal perspectives. When positive developments are described, the narrator 
instructs that towels should be unfolded (a bit) to show signs of hope. By the end of the Blanket Exercise, the number of original inhabitants is much reduced, and the many fewer, much-folded towels vaguely resemble the reserves peppered across the land that was once proudly Turtle Island. Through this interactive story activity, participants come to a greater and more sympathetic understanding of the enormous losses to FNMI peoples, and become aware of how little land is left to them as reserves.

At the end of the exercise, participants sit in a circle around the once-blanketed area and reflect on the experience. Following one of many FNMI traditions, a talking feather is passed from participant to participant. Only the person holding the feather is permitted to speak (while the feather is in his or her possession), but participants have an opportunity to hold the talking feather and speak about their perceptions, impressions, experience, observations, or feelings. This organic sharing process has proved to be far more open-hearted and productive for participants than the written post activity.

Numerous student participants were shocked at the loss of land and to learn that many Aboriginals died of disease, as evidenced in their written post-activity responses:

- "I did not know that so many people lost so much land and that so many people died from different diseases. I'll remember that the Aboriginal people only got a small amount of land after the settlers 'took over'."

- "I did not know that there was an island called Turtle Island that was getting taken over, and it started out really big and then they just kept losing land."

- "I would describe it to someone who missed it by telling them that it was really cool learning about the Native people."

- "I would describe the Blanket Exercise to someone who missed it and say it was a great and empowerful (sic) touching experience and we should be grateful. They sent the kids to school and they could not speak their family's language and they took it away. The land was Turtle Island."

The objectives of the project study (the Blanket Exercise kit) are to create greater awareness and respect, and to recognize FNMI culture through the experience of the story. Stories are what human beings remember, and how they remember them (Haven, 2007). Ideally, the Blanket Exercise will continue to create a gateway to learning by providing an experiential context that is keenly remembered. As a result, teachers and students alike will read more deeply into the text as they explore the Social Studies/ History curriculum. The Blanket Exercise supports initiatives and objectives of the Ontario First Nation, Métis and Inuit Policy Framework from the Aboriginal Education 
Office at the Ministry of Education (2007), acknowledging a troubled past, and gently allowing for self-identification in a safe context, should that occur.

The kit for the Blanket Exercise includes scripts, scrolls, sorting mechanisms (coloured sticks, shells, feathers, stones, beads), talking feathers, capes (for the Europeans), and towels obtained through a grant from a teachers' union, Ontario English Catholic Teachers' Association (OECTA), under the Justice and Peace initiative. In cooperation with the FNMI consultant, and the itinerant teacher of the gifted, numerous groups have had the opportunity to experience the Blanket Exercise. The kit is catalogued at the resource center, along with clear instructions for its use, so that teachers who have participated in the professional development will be familiar with the kit and able to use it with the classes at their respective schools. As a result of its positive reception, additional kits are being created. The student team proudly assisted in numerous presentations at the school site. As a result of their work with the narrative, they have developed a deeper understanding of the content and its implications, and some of the students have demonstrated a keen interest in continuing to learn about Aboriginal history.

\section{Educating Through Storytelling}

In Western thinking, direct address is used to communicate important ideas in education, important concepts that must be learned. Educators learn to be explicit. The bulleting function on our computers is well used as we present key ideas in point form, leaving no doubt as to the main concepts. In Aboriginal experience, stories are more incidental, and the listeners, if their families still keep some of the old ways, or participate in some of their own cultural activities, are more greatly attuned to environmental learning:

Storytelling is used to teach children who they are, where they are from, what their elders know about the world and how to behave in it. Storytelling is one of the primary means for teaching children about appropriate Tohono O'odham behavior, as many stories warn children about the consequences of misbehaviour and the benefits of behaving appropriately. (Tsethlikai \& Rogoff, 2013, p. 570)

Tsethlikai and Rogoff (2013) described the benefits of "learning through attentive involvement and contribution to family and community events" (p. 575). They found that children who participated in traditional practices, which included listening to traditional oral stories and teachings, had better recall for a story that was told orally, but indirectly. This recall is not attributed simply to the fact that these children might be 
considered to be experienced listeners, but also to the fact that recent research seems to indicate that reading comprehension is enhanced by oral comprehension skills, as are oral and written expression (Berninger \& Abbott, 2010). Experienced listeners would be anticipated to benefit most from learning through story, and hearing a story told by a skilled storyteller also enhances the experience, and leads to greater comprehension, impact, and consequently, retention.

Some of these stories will ultimately lead to the revelation of historical truths. Daschuk (2013) noted that when stories of sexual and physical abuse of First Nations children at residential schools were mentioned 20 years ago, some scholars suggested that the stories be taken with a grain of salt, believing, just as others did, that the stories of near-starvation and children who died in those places and whose deaths were never explained to their parents, were highly exaggerated. When students and others read histories that stated benignly: "the land was prepared for settlement," it occurred to none that this meant an ethnic cleansing - that food was denied, despite treaty agreements that included food aid. Until this present day, many Canadians have discounted "reports of terrible housing conditions on reserves, unsafe drinking water, dismal educational outcomes, and...prison populations disproportionally stacked with Aboriginal inmates" (Daschuk, 2013, para. 8). We have not listened to the stories.

Just as master storytellers include folktales in their repertoires, and understand their essential nature in the storytelling, so too do Aboriginal teachers employ archetypes. These are paramount in the implicit teaching of cultural values, including "oral tradition, language, history, institutions, norms and values, territory, environment and ecology" (Atleo, 2009, p. 455). Atleo identified the seven principles of storywork from the Coast Salish First Nations Elders as "reverence, respect, responsibility, reciprocity, wholism, interrelatedness and synergy" (p. 455). Atleo used metaphoric mapping to examine the implicit themes in an Aboriginal tale as explored by these elders who explained to her that the function of grandparents includes their knowledge, guidance, and their example of how to conduct themselves. Knowledge tended to be gender-specific and not all grandparents or elders were knowledgeable about all things or even the same things. An understanding of the role of grandparents in the culture underlines the calamity of residential schools that resulted in the loss of grandparent wisdom and experience.

\section{A Right Time and Place}

A storyteller has the responsibility to tell the right stories at the right time and in the right place. This requires that the storyteller have a significant repertoire of stories, 
and presumably many of the key stories of the culture, or at least stories with universal themes. It also requires the storyteller be proficient in the telling so that the stories have the necessary impact. Implicit is the requirement that the storyteller be sufficiently intuitive or attuned to the situation to know what is appropriate. Dion (2004) identified dual responsibilities: that of the listener to seek and find meaning in the story, and that of the teller to tell an appropriate story for the circumstances and the listeners. Ojibway Storyteller (2005) explained that Traditional First Nations storytellers were required to know the teachings of their own peoples and others, and to share the wisdom and the words of the past with the present generation for the future. The history had always been passed down orally, and before it ever was written down, the past and the traditional teachings had been learned word for word. The responsibility of the storytellers was to pass on the understanding they carried in their hearts and in their spirits in words that would inspire the next generations, the future chiefs and leaders, "the future clan mothers, and the future mothers and fathers" (para. 3). In the far too numerous situations where generation after generation was removed from their family, village, and culture, and sent away to residential schools with the express purpose that the institutions would "kill the Indian in the child" (Campbell, 2013), such traditional teachings were not passed on. The stories were not told at the right time; the stories were not told at all.

The Truth and Reconciliation Commission of Canada (2012) explicitly states in their report, They Came for the Children: "This is a story of loss. Residential schools disrupted families and communities. They prevented elders from teaching children long-valued cultural and spiritual traditions and practices. They helped kill languages" ( $p$. 1). The loss is all the more critical because in many cases the Aboriginal languages and dialects had not yet been codified. When the oral language was lost, the knowledge was lost along with it. The book describes the residential school experience and cites numerous FNMI individuals who share their lived experience.

Guerilla storytelling is a term coined to describe necessary storytelling. Guerilla storytelling requires that the teller have an extensive repertoire, and that it be accessible, ready to tell at a moment's notice, suggesting that a significant amount of storyteller competence is required. Clarkson (2004) described a situation in which he was invited to tell stories to a government-sponsored group (CASCADE). His response to offer his pro bono services underlines the reason a storyteller tells stories in the first place: a storyteller believes in the power of story to heal the world. The coordinator was an experienced story listener who valued storytelling and story. The teller was an experienced storyteller with an extensive repertoire of traditional folktales and legends, as well as original work. While Clarkson (2004) did not use the word "magical," 
he strongly implied that this was a serendipitous experience of being exactly where he was meant to be and telling the right story at the right time.

King (2003) credits Okri, a Nigerian storyteller with having said:

In a fractured age, when cynicism is god, here is a possible heresy: we live by stories, we also live in them. One way or another we are living the stories planted in us early or along the way, or we are also living the stories we planted-knowingly or unknowingly -in ourselves. We live stories that either give our lives meaning or negate it with meaninglessness. If we change the stories we live by, quite possibly we change our lives. (p. 153)

There are families where members, not realizing that they themselves are of Aboriginal descent, hold negative views about their own people, unknowingly. Through the experience of the Blanket Exercise, participants develop a new appreciation of the unacknowledged, largely unknown, history of the land we call Canada, and may be better prepared to participate in meaningful dialogue through the healing process ahead. Negative life experiences are frequently suppressed, minimized, and silenced in fear and shame, but when a storyteller puts words and gives context to these hardships and redeems them, showing a path out of the labyrinth, an alternate ending (restorying), the listener who shares the story at multiple levels is affirmed and may begin the healing journey.

In her early days with the storytellers' guild, one participant, Connie, ${ }^{1}$ not yet fully realizing that Stories Aloud was restricted to adults, once brought her teenage foster daughter because she felt very strongly that the girl needed to hear a certain story. Sonia had come to Canada with her family as a refugee sponsored by Connie's church. Her parents were struggling to raise their children in an unfamiliar culture, climate, and language, and Sonia became rebellious. When Sonia's father became ill, Connie, who had already raised her own children, took the teenager in. She wanted and was determined to have Sonia hear the story of the Porcelain Man, and felt no remorse that she had gone against the rules to accomplish this-especially since she had been unaware of the strictness of the adults only rule at the time of her transgression.

I was not sorry because I had brought Sonia for a very specific reason: because she needed to hear that story. One of the lines was: "Her father could control where she was but he could not control what she thought." And that applied to Sonia in her own life: they could control where she was, but not what she thought, and she loved it. 
That two other storyteller-participants mentioned key stories that had the potential to help a person navigate difficult times is particularly interesting, especially because that question had not yet been asked in the interviews, yet there it was. The act of telling necessary stories is described by another participant, Angie, as "guerrilla storytelling." Amber noted: "It is the responsibility of storytellers to tell the right stories. That's a really serious responsibility. You need to be completely committed to telling the right story at the right time." The idea of the power of story was expressed numerous times in just as many ways.

Lynn commented on the hunger for story:

You know, I think they are hungry for that, the talisman, that thing that they can take away. I don't think that our culture has much faith in our children. We make everything explicit. We don't have the sense that their own brains are capable of working out and their own souls are capable of striving, and they're going to grow and change and go through things; they're going to go on a journey, will suffer, and experience great joy. Stories that impart that faith. Unwanted, unfortunate, impoverished, go [on] a journey, be successful and find a different world. We don't have faith that any of these things are going to happen for our children. Parents don't give this message. I'm sixty, and it's a message my parents and certainly my grandparents gave me: "You're going to be okay."

Storytellers appear to have been drawn to storytelling less for the sake of performing and more for the sake of the stories themselves. Amber explained it this way:

Stories attract me because I think that is where everything resides. In this digital age, if everything crashed tomorrow, [computers] it would be the storytellers who carry the wisdom of the world. I do think all the wisdom of the world is in stories, the humor, the cultural values, the lessons we need to know about life. Each culture carries its own stories, its own lessons. How we do things in this culture, and what is okay and what is not okay.

\section{Recognizing the Story}

As the lead researcher was analyzing the data for her research project, the Canadian news media was breaking the story that evidence of starvation experiments had been conducted on First Nations children at residential schools (Weber, 2013a, 2013b). Although it added credence to her position that suppressed stories would ultimately come forth, the news was devastating, heartbreaking. The news story, coming at the 
right time, confirmed her conviction that the Blanket Exercise needed to be shared and promoted, that this story too, must be told. Told until it is known, told until it is acknowledged by Canadians as part of our history. With Canada's 150th birthday on the horizon (2017), there is a certain urgency.

Such an acknowledgment could lead to the beginning of the much needed healing between Aboriginal and non-Aboriginal cultures in Canada. In 1998, a delegation of Sahtu Dene from Déline, NWT, the village of widows, set an example and provided us with a model for a reconciliation. Although 50 years and more had passed, when these elders learned that the uranium from the mines in which their men, community members, had worked had been used in the Manhattan Project for the bomb that was dropped on Hiroshima, they determined to go to Hiroshima to visit the hibakusha, the explosion-affected people, to acknowledge the fact. Although they had lost many of the men from their own community (in many cases because of the handling of the uranium), and had suffered great trauma, and they had been completely unaware of their connection to events so far away, it was very important to the community that they acknowledge the truth. The delegation wanted to see that faraway place, and to speak to the hibakusha and tell them that they would never have participated in such an unimaginable atrocity had they been aware.

Perhaps, just as the Blanket Exercise offers the first step toward resolving our collective lack of awareness of the land we call Canada, the story of the Village of Widows provides an example of how to respond: to become informed, and to acknowledge to those affected that although we did not realize before, we now know what happened. And we will finally be able to acknowledge their loss. The Blanket Exercise may provide a template, or at least, the inspiration for a narrative means with which to teach about the Residential Schools, another long-suppressed story where place intersects with narrative. For as every storyteller and every seasoned story listener knows, one story has always led to another: the right story at the right time.

\section{Note}

1. All names are pseudonyms. 


\section{References}

Aboriginal Education Office at the Ministry of Education (2007). Ontario First Nation, Métis and Inuit Policy Framework. Retrieved from: http://www.edu.gov.on.ca/eng/aboriginal/ policy.html

Atleo, M. R. (2009). Understanding Aboriginal learning ideology through storywork with elders. The Alberta Journal of Educational Research, 55(4), 453-467.

Benson, L. A. (2003). Circle of healing: Traditional storytelling, part one. Arctic Anthropology, 40(2), 9-13.

Berninger, V. W., \& Abbott, R. D. (2010). Listening comprehension, oral expression, reading comprehension, and written expression: Related yet unique language systems in grades 1, 3, 5, and 7. Journal of Educational Psychology, 102(3), 635-651.

Campbell, L. J. (2013, March 28). Schools tried to "kill the Indian in the child." North Bay Nipissing. Retrieved from: http://www. northbaynipissing.com/2013/03/schoolstried-to-kill-the-indian-in-the-child-/

Chamlee-Wright, E., \& Storr, V.H. (2009). "There's no place like New Orleans": Sense of place and community recovery in the Ninth Ward after Hurricane Katrina. Journal of Urban Affairs, 31(5), 615-634. doi:10.1111/j.1467-9906.2009.00479.x

Clarkson, W. (2004). Random acts of storytelling. Storytelling.net. Retrieved from: http://www. storyteller.net/articles/159.

Corntassel, J., Chaw-win-is, \& T'lakwadzi, (2009). Indigenous storytelling, truth-telling, and community approaches to reconciliation. English Studies in Canada, 35(1), 137-159.

Daschuk, J. (2013, July 19). When Canada used hunger to clear the west. The Globe and Mail. Retrieved from: http://www. theglobeandmail.com/commentary/whencanada-used-hunger-to-clear-the-west/ article13316877/?service $=$ print

Dion, S. D. (2004). (Re)telling to disrupt: Aboriginal people and stories of Canadian history. Journal of the Canadian Association for Curriculum Studies, 2(1), 55-76.
Haven, K. (2007). Story proof: The science behind the startling power of story. Westport, CT: Libraries Unlimited.

Kairos Canada. (2013). The blanket exercise: The indigenous rights history we've never been taught. Retrieved from: http:// www.kairoscanada.org/dignity-rights/ indigenous-rights/blanket-exercise/

King, T. (2003). The truth about stories: A native narrative. Toronto, ON: House of Anansi Press.

Long, D. A., \& Perkins, D. D. (2007). Community social and place predictors of sense of community: A multilevel and longitudinal analysis. Journal of Community Psychology, 35(5), 563-581. doi:10.1002/jcop.20165

Ojibway Storyteller (2005). Retrieved from: http://www.ojibwaystoryteller.com/ Storyteller/osindex.htm

Ontario Ministry of Education (2013). The Ontario Curriculum, Social Studies, Grades 1-6; History and Geography, Grades 7-8, 2013. Retrieved from: http://www.edu.gov.on.ca/ eng/curriculum/elementary/sshg.html

Smith, J. M. (2007). The Magdalene sisters: Evidence, testimony... action? Signs: Journal of Women in Culture and Society, 32(2), 431-458.

Truth and Reconciliation Commission of Canada. (2012). They came for the children: Canada, Aboriginal peoples, and residential schools. Winnipeg, MN: Truth and Reconciliation Commission of Canada.

Tsethlikai, M., \& Rogoff, B. (2013). Involvement in traditional cultural practices and American Indian children's incidental recall of a folktale. Developmental Psychology, 49(3), 568-578. doi:10.1037/a0031308

Van Deusen, K. (2008). Kiviuq's journey: An Inuit hero's epic quest. Retrieved from: http:// www.unipka.ca/Index.html

Waters, D. (2010). Berlin and the Holocaust: A sense of place? Teaching History, 141, 5-10. 
Weber, B. (2013a, July 16). Canadian government withheld food from hungry Aboriginal kids in 1940s nutritional experiments, researcher finds. The Globe and Mail. Retrieved from: http://www. theglobeandmail.com/news/national/ hungry-Aboriginal-kids-adults-weresubject-of-nutritional-experiments-paper/ article13246564/
Weber, B. (2013b, July 17). Atleo calls on PM to acknowledge 'horrors' of nutrition tests on native children. The Globe and Mail. Retrieved from: http://www. theglobeandmail.com/news/national/ atleo-calls-on-pm-to-acknowledge-horrors -of-nutrition-tests-on-native-children/ article13291949/

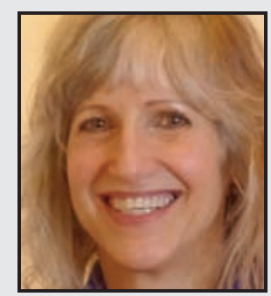

Mary McCullum Baldasaro holds an EdD in Educational Leadership from Walden University. Mary teaches Core French in the elementary panel (French as a Second Language). She is a storyteller who tells traditional, literary, and original stories and has performed at the Toronto Storytelling Festival, Sharon Temple Storytelling Festival, Latitudes Storytelling Festival, Joseph Schneider Haus, and World Storytelling Day at Waterloo Regional Museum. She is also a frequent teller at Stories Aloud at the Button Factory. Mary enjoys working with language, both the spoken and the written word, because of its capacity to touch hearts and effect change.

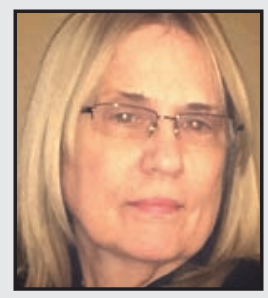

Nancy Maldonado holds a PhD in Educational Leadership and an MA in English from Barry University. Nancy taught high school English for 13 years and has 14 years of experience teaching and supervising doctoral research students. Nancy enjoys research and writing, as well, and has published a number of peer-reviewed articles and has presented at research conferences such as the American Educational Research Association (AERA) conference, Mid-South Educational Research Association (MSERA) conference, and Florida Educational Research Association (FERA) conference. Nancy has served as proposal reviewer for AERA and FERA as well as manuscript reviewer for Jossey-Bass Publishers. 


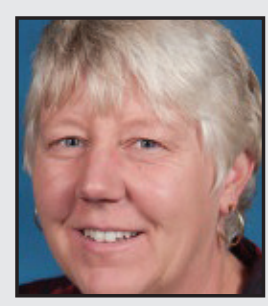

Beate Baltes holds an EdD in Educational Administration from United States International University and an MA in Education from the University of Munich, Germany. Beate has over two decades of experience in higher education teaching of Master- and Doctoral-level courses, as well as supervising doctoral research. During her sabbatical, Beate founded and directed the Department of Electronic Learning at the University of Chemnitz. Beate has published in peer-reviewed journals and presented at national and international conferences. Her most interesting assignment was to teach the Benedictine Confederation in Rome how to develop an online university. 